\title{
Komputasi Paralel Menggunakan Nvidia Cuda Untuk Pemodelan 2d Tsunami Aceh Dengan Metode Lattice Boltzmann
}

\author{
Efraim Ronald Stefanus Moningkey ${ }^{1}$ \\ Universitas Negeri Manado \\ e-mail: efraimmoningkey@unima.ac.id \\ Rudi H. W. Pardanus ${ }^{2}$ \\ Universitas Negeri Manado
}

\begin{abstract}
ABSTRAK
Tsunami merupakan kejadian alam yang terjadi ketika adanya aktifitas di dasar laut dan sangat berbahaya, karena dapat mengakibatkan kerusakan yang besar. Mengingat bahaya tsunami maka dalam penelitian ini dibuat sebuah perancangan pemodelan menggunakan paralelel computing untuk memodelkan tsunami yang terjadi di Aceh, menggunakan NVdia CUDA dan menggunakan metode lattice Boltzmann D2Q9. Pemodelan ini diharapkan dapat membantu untuk mengetahui arah perambatan gelombang tsunami, dan daerah pesisir yang akan terkena dampak
\end{abstract}

Keywords: Tsunami, Parallel computing, Lattice Boltzmann, NVidia Cuda

ABSTRACT

Tsunamis are natural events that occur when there is activity on the bottom of the sea. They are very dangerous because they can cause big damage. Given the tsunami risk, this study consisted of parallel computer modeling to model tsunamis in Aceh, using NVdia CUDA and the Boltzmann D2Q9 network method. This modeling should help decide the direction of tsunami wave propagation and the coastal areas that will be affected.

\section{Keywords: Tsunami, Parallel computing, Lattice Boltzmann, NVidia Cuda}

\section{PENDAHULUAN}

Tsunami ini merupakan kejadian alam yang dipengaruhi adanya aktifitas yang terjadi di dasar laut, aktifitas ini dapat berupa gempa laut, gunung berapi meletus, atau hantaman meteor di laut, tanah longsor di dasar laut. Tsunami Aceh adalah salah satu bencana terhebat abad 21, diawali dengan gempa 9.1 SR mengakibatkan kematian di Aceh mencapai 200 ribu jiwa, belum termasuk di daerah lain seperti Thailand, Sri Lanka, India, Maladewa, dan pesisir timur Afrika. (Zakia, 2012). Tsunami merupakan peristiwa alam yang bisa menimbulkan kerusakan yang sangat besar, untungnya dengan memanfaatkan kemajuan teknologi saat ini, tsunami ini dapat didekati dengan menggunakan pemodelan, diharapkan dengan pemodelan ini dapat dilihat bagaimana cara penyebaran tsunami, sehingga dapat memberikan deteksi dini untuk meminimalisir korban.

Pemodelan tsunami dapat dimodelkan salah satunya dengan menggunakan metode Lattice Boltzmann, metode ini banyak digunakan untuk memodelkan pergerakan perairan dangkal, dalam contoh kasus tsunami ini metode Lattice Boltzmann akan berjalan lebih baik jika menggunakan parallel computing. Dengan menggunakan parallel computing untuk pemodelan diharapkan dapat mempercepat proses berkali-kali lipat, pada dasarnya pemodelan dengan menggunakan Parallel computing dapat dilakukan dengan dua cara yaitu dengan menggunakan teknologi CPU (Central Processing Unit) dan GPU (Graphic Processing Unit).

Pada penelitian ini penulis memanfaatkan parallel computing menggunakan teknologi GPU. Salah satu 
teknologi pemrograman parallel yang menggunakan GPU adalah teknologi yang dipunyai oleh sebuah vendor pengembang graphic card NVidia. NVidia mengembangkan CUDA (Compute Unified Device Architecture).

NVidia CUDA merupakan teknologi yang sekarang paling dinikmati, karena kenyamanan dalam proses pemodelannya, ditambah NVidia CUDA ini merupakan tools yang terbaik saat ini dalam parallel computing dengan GPU. Inilah yang menjadi dasar penulis untuk mengembangkan komputasi paralel menggunakan NVidia CUDA untuk pemodelan $2 \mathrm{~d}$ tsunami dengan metode Lattice Boltzmann.

\section{Penelitian Tsunami}

Tsunami ini merupakan kejadian alam yang dipengaruhi adanya aktifitas yang terjadi di dasar laut, aktifitas ini dapat berupa gempa laut, gunung berapi meletus, atau hantaman meteor di laut, tanah longsor di dasar laut, patahan. Terjadinya aktifitas tersebut dapat membuat tsunami yang menghancurkan seperti di pantai utara New guinea pada 1998 (Ward, 2000 ; Geist, 2000; Tappin, et. al., 1999). Pergeseran di bawah laut ini memang menyebabkan perpindahan air laut, bahkan kecepatannya bisa mencapai $800 \mathrm{~km} / \mathrm{jam}$, parahnya ketika mencapai daratan, kecepatan tsunami mengalami penurunan tapi ketinggiannya bertambah disebabkan oleh penumpukan massa air. (Ramya dan palaniappan, 2011). Pada laut lepas misal terjadi gelombang pasang sebesar $8 \mathrm{~m}$ tetapi begitu memasuki daerah pelabuhan yang menyempit tinggi gelombang pasang menjadi $30 \mathrm{~m}$. (Nur, 2010) Bahkan akibat dari tsunami dapat merubah ekosistem laut, seperti pada tsunami aceh 26 desember 2004 (Huda, dkk, 2009).

\section{Segmentasi Citra}

Segmentasi merupakan proses membagi wilayah-wilayah tertentu yang ingin ditonjolkan dari sebuah citra. Para ahli komputer vision menggunakan metode segmentasi citra untuk melakukan penelitian pengolahan citra.

Menurut Huang (2009), untuk mendapatkan bentuk dari suatu citra, dilakukan proses segmentasi citra menggunakan metode level set. Posisi dan ukuran wilayah yang telah tersegmentasi akan dihitung dan ditetapkan model bentuk citra sehinggamendapatkan hasil yang lebih baik.

Menurut Muthukrishnan dan Radha (2011), interpretasi isi citra merupakan tujuan komputer vision dalam pengolahan citra, hal ini dilakukan untuk membaca dan mengidentifikasi isi citra. Deteksi tepi yang digunakan merupakan alat fundamental untuk segmentasi citra.

\section{Metode lattice boltzmann untuk air dangkal}

Perairan dangkal merupakan perairan yang mempunyai kedalaman $<60 \mathrm{Km}$. Teori perairan dangkal biasanya yang digunakan untuk pemodelan tsunami secara numeric. Persamaan air dangkal biasanya diguakan untuk mensimulasikan gelombang yang panjang gelombangnya mirip dengan ketinggian air secara keseluruhan (Thurey, dkk., 2006). Dalam hal ini kecepatan propagasi gelombang untuk amplitude adalah konstan. Simulasi air dangkal juga dapat dibentuk dengan menggunakan persamaan lattice boltzmann. Tidak hanya mempertimbangkan tekanan fluida tetapi nilai ketinggian dihutung untuk setiap sel. Penelitian yang memanfaatkan metode lattice boltzmann untuk memodelkan tsunami juga pernah dilakukan yaitu mengenai Model 2D visualisasi tsunami aceh dengan metode Lattice Boltzmann, 
Nazarudin menggunakan CPU (Nazarudin, 2013).

\section{Metode lattice boltzmann dengan GPU}

Metoda Lattice Boltzmann (Thurey, 2003), sesuai dengan namanya, bekerja dalam area lattice. Ada beragam jenis lattice yang dapat digunakan, tergantung pada lingkungan pengaplikasiannya. Penamaannya pun disesuaikan menurut aturan DXQY, di mana $X$ adalah jumlah dimensi, misalnya 3, dan Y menunjukkan banyaknya arah kecepatan lattice. LBM merupakan salah satu jenis cellular automata, yang berarti fluida terbentuk dari banyak sel sejenis. Semua sel diperbaharui disetiap langkah waktu dengan aturan sederhana, dengan ikut memperhitungkan sel-sel disekitarnya. LBM memodelkan fluida yang tak mampu-mampat (incompressible) dimana partikel fluida hanya dapat bergerak searah dengan vektor kecepatan lattice. Keuntungan dari metode ini adalah kemudahan dalam komputasi paralel karena lokalitas interaksi partikel dan transportasi informasi partikel, fleksibilitas dalam geometri karena implementasi yang relatif mudah dengan menentukan kondisi batas yang kompleks dan sifat kompleks dari sistem cairan. Dengan menggunakan metode lattice Boltzmann dapat mengoptimalkan proses pemodelannya (Revell, 2013). metode ini juga sangat baik untuk aliran yang kompleks, dan yang bisa diparalelkan, metode ini juga mudah untuk diimplementasikan (Januszewski, 2012).

\section{NVidia CUDA untuk Metode lattice boltzmann}

Nvidia Cuda merupakan tools pemrograman parallel yang sangat baik digunakan dalam penerapan metode lattice boltzmann, lebih baik dari menggunakan teknologi GPU yang lain. (Bernaschi, dkk,
2009). Penggunaan CUDA memberikan kenyaman dalam pemrograman parallel karena CUDA menyediakan akses ke level arsitektur komputasi (Gohari dan Ghadyani, 2012).

\section{METODE}

\section{Metode Kepustakaan}

Penulis menggunakan metode ini untuk mencari literatur atau sumber pustaka dan pengumpulan gambar yang berkaitan dengan obyek yang diteliti. Kegunaan metode ini adalah dapat membantu mempertegas teori serta keperluan analisis dan mendapatkan data yang sesungguhnya.

\section{Metode Pembuatan Perangkat Lunak}

Pengembangan perangkat lunak menggunakan bahasa $\mathrm{C}$ dengan memodifikasi kode program dari Dr. Graham Pullan (2008). Langkah- langkah pada pembuatan perangkat lunak adalah sebagai berikut :

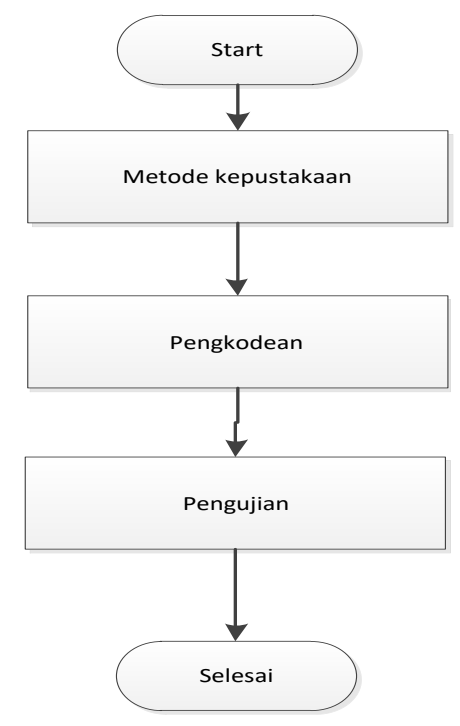

Gambar 1 Flowchart Metodologi penelitian 


\section{HASIL DAN PEMBAHASAN}

Untuk dapat membuat model simulasi tsunami, yang harus dilakukan adalah mendapatkan peta lokasi daerah bencana tsunami. Peta yang digunakan sebagai pemodelan untuk simulasi tsunami akan dilakukan proses pengolahan citra digital. Contoh peta wilayah Banda Aceh dan Sumatera Utara yang menjadi wilayah bencana tsunami dengan ukuran 2308x2972 dapat dilihat pada gambar dibawah ini (Sumber: www.indonesia-tourism.com /aceh/ map.html):

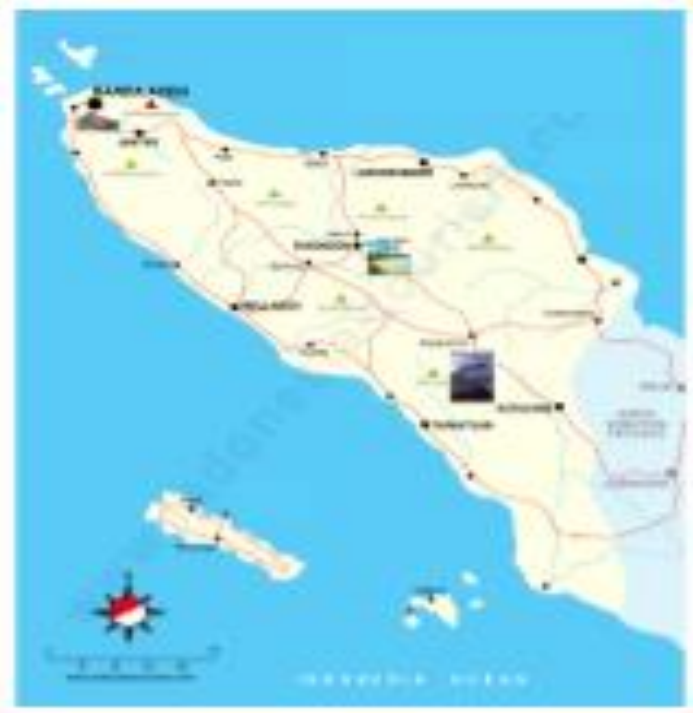

Gambar 2 Peta wilayah Aceh

Gambar diatas diolah secara manual untuk selanjutnya diolah, gambar ini disimpan dengan ekstensi .PNG, menghasilkan map.PNG

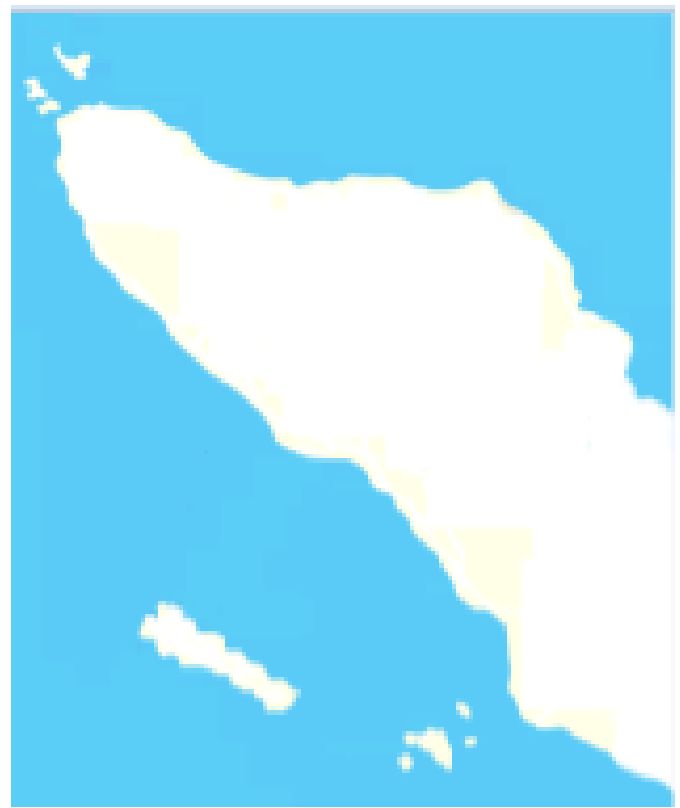

Gambar 3 map.png hasil pengolahan manual.

Gambar di atas selanjutnya diolah menggunakan MATLAB, sehingga dapat digunakan untuk proses simulasi.

\section{Pengambangan (Thresholding)}

Awalnya gambar dikenakan proses pengambangan (Thresholding) ini berfungsi untuk memisahkan piksel-piksel berdasarkan derajat keabu-abuan yang dimilikinya. Piksel yang memiliki derajat keabu-abuan yang lebih kecil dari nilai batas akan ditentukan mempunyai nilai 0 , sementara piksel yang memiliki derajat keabu-abuan yang lebih tinggi akan diubah menjadi nilai 1 .

\section{Citra Biner}

Proses selanjutnya yaitu dengan mengkonversi citra hitam putih menjadi citra biner, pada pemodelan tsunami ini peta yang sudah di-threshold selanjutnya akan dikonversi ke dalam citra biner, ini bertujuan untuk membuat bagian citra dengan nilai piksel 0 menjadi lautan, dan bagian piksel 1 menjadi daratan dalam proses simulasi, kemudian menggunakan 
MATLAB citra ini akan disimpan dalam file map400.dat.

\section{Inisialisasi Kondisi}

Pada bagian ini akan ditentukan inisialisasi kondisi untuk masalah fisis yang akan dimodelkan dalam bentuk variabel makroskopik yang merupakan langkah dalam metode numerik. Karena persamaan Lattice Boltzmann didasarkan pada persamaan

$f_{i}\left(x+e_{i}, t+1\right)-f_{i}(x, t)=-\frac{1}{\gamma}\left(f_{i}(x, t)-f_{i}^{e q}(x, t)\right)$

maka kondisi awal harus ditulis dalam fungsi distribusi $f i^{e q}$, menentukan densitas $\mathrm{h}$, dan kecepatan untuk arah $x\left(u_{x}\right)$ dan kecepatan arah $y\left(u_{y}\right)$.

Titik lattice digunakan juga untuk memberikan batas area penyebaran aliran untuk daerah solid sehingga aliran fluida akan terpantul kembali.

\section{Menentukan Makroskopik}

Pada tahap ini, akan ditentukan variabel makroskopik densitas fluida dan kecepatan fluida seperti persamaan

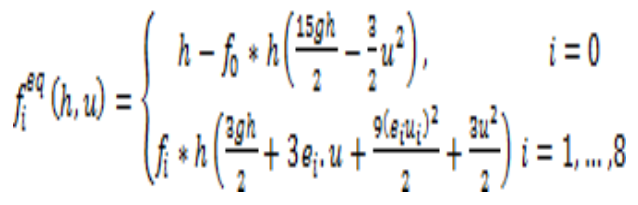

yaitu menentukan nilai kepadatan fluida $\rho=h$, kecepatan fluida (u), fungsi distribusi partikel $f_{i}$, Untuk mendapat nilai kecepatan untuk arah $\mathrm{x}$ dan kecepatan untuk arah y maka harus dihitung densitas fungsi distribusi partikel sesuai dengan arah lattice, kemudian dibagi dengan densitas fluida keseluruhan.

\section{Menentukan Tumbukan}

Pada proses tumbukan diperlukan fungsi distribusi keseimbangan. Untuk menghitung nilai fungsi distribusi keseimbangan diperlukan nilai kepadatan $\rho=h$ dan nilai gravitasi (gr). Terlebih dahulu dihitung nilai fungsi distribusi keseimbangan sesuai persamaan

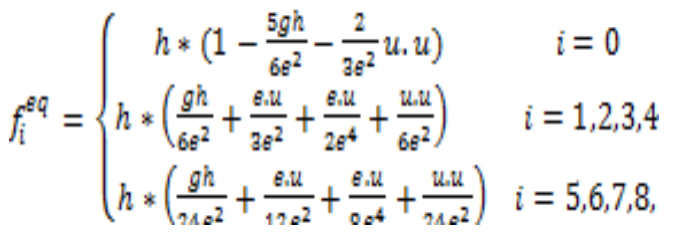

dan sesuai dengan nilai bobot pada persamaan

$W_{1}\left\{\begin{array}{c}\frac{4}{9}, i=0 \\ \frac{1}{9}, i=1,2,3,4 \\ \frac{1}{\pi}, i=5,6,7,8\end{array}\right.$

\section{Menentukan Aliran}

Fungsi aliran sesuai dengan persamaan

$f_{i}^{\prime}(x, t)=f_{i}\left(x+e_{i}, t+1\right)$

digunakan untuk menghitung nilai perpindahan titik lattice.

\section{Menentukan Kondisi Batas}

Batas solid diasumsikan sebagai daerah yang tidak dilewati oleh gelombang, dengan kata lain daerah solid adalah daerah yang bukan fluida. Pada visualisasi perambatan gelombang, gelombang akan merambat pada daerah solid dan sebagian dari gelombang akan dipantulkan kembali (bounce-back).

Visualisasi adalah bagaimana konversi data ke dalam format visual atau tabel sehingga karakterisitik dari data dapat dianalisis dan dilaporkan. Dalam penelitian ini visualisasi yang dihasilkan adalah berupa gambar visual atau dalam format visual. Pada proses visualisasi perambatan gelombang tsunami ini, skala richter dari gempa diabaikan karena yang ingin dihasilkan adalah model perambatan gelombang. Tinggi gelombang tidak terlalu diperhitungkan karena besar kecilnya amplitudo yang ditentukan tetap memiliki pola perambatan gelombang 
yang sama. Nilai awal yang diberikan adalah tau $=0.5$, gr $=0.5$, hout $=1.0$, waktu iterasi yang digunakan berbeda sesuai dengan kebutuhan.

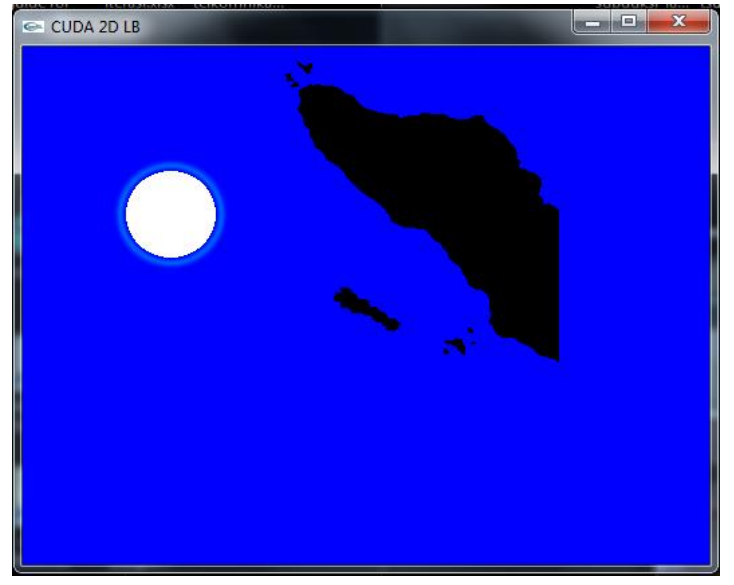

Gambar 4. Perambatan gelombang saat iterasi $=50$

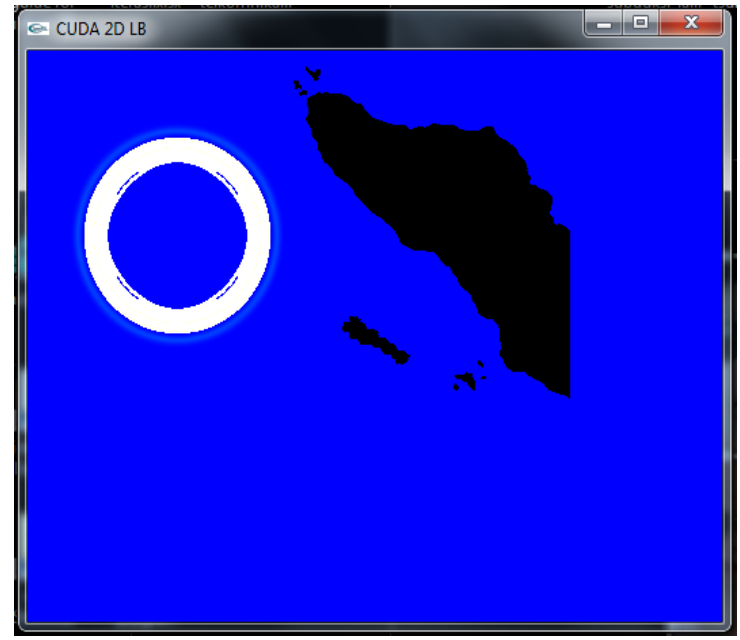

Gambar 5. Perambatan gelombang saat iterasi $=100$

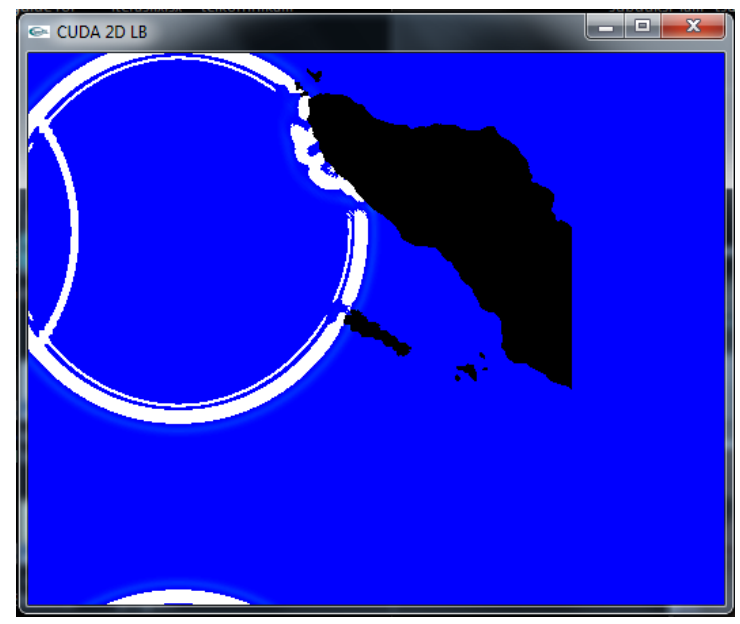

Gambar 6. Perambatan gelombang saat iterasi $=200$

\section{PENUTUP}

\section{Kesimpulan}

Berdasarkan hasil penelitian dapat di Tarik kesimpulan, metode lattice Boltzmann dengan menggunakan persamaan navierstokes dapat digunakan untuk melakukan visualisasi tsunami dan dapat berjalan dengan baik pada gpu nvdia cuda, dan pengolahan citra tidak hanya digunakan untuk memperbaiki citra tetapi dapat juga digunakan proses visualisasi.

\section{DAFTAR PUSTAKA}

Arifin, S. (2005). Strategi untuk mengurangi kerusakan lingkungan yang diakibatkan oleh gempa dan gelombang tsunami. Jurnal Arsitekture "Atrium", 28-33.

Balevic, A. (2009). Parallel VairableLength Encoding on GPGPUs. HPPC 2009 - the 3rd Workshop on Highly Parallel Processing on a Chip, 19.

Bernaschi, M., \& dkk. (2009). A flexible high-performance Lattice Boltzmann GPU code for the simulations of fluid flows in complex geometries, 
CONCURRENCY

COMPUTATION:

AND

AND EXPERIENCE, Retrieved

from Wiley InterScience:

www.interscience.wiley.com

Gohari, S. M., \& Ghadyani, M. (2012). Effects of GPU Structuring on Accelerated Schemes of Lattice Boltzmann and Classical CFD for Flow over a Flat Plate, Journal of Mathematics and System Science 2.

Huang, Chieh-Ling. (2009). Shape-Based Level Set Method for Image Segmentation, Ninth International Conference on Hybrid Intelligent Systems.

Huda, I., \& dkk. (2009). kondisi vegetasi dan keranggeloina pasca tsunami dalam kawasan ekosistem mangrove pesisir barat kabupaten aceh besar, Torani (Jurnal Ilmu Kelautan dan Perikanan) Volume 19, 82 - 89.

Januszewski, M. (2012). Sailfish: Lattice Boltzmann Fluid Simulations with GPUs and Python, Institute of Physics University of Silesia in Katowice, Poland, Google. GTC 2012.

Nazaruddin, A., \& Pranowo. (2013). Model 2D visualisasi tsunami aceh dengan metode Lattice Boltzmann. Proceeding Sentika (p. 240). Yogyakarta: Universitas Atma Jaya.

Nur, A. M. (2010). Gempa bumi, tsunami dan mitigasinya. Jurnal geografi volume 7 no. 1 .

R, Muthukrishnan., Radha, M., 2011, Edge Detection Techniques for
Image Segmentation, International Journal of Computer Science \& Information Technology (IJCSIT) Vol 3, No. 6, Dec 2011.

Ramya, V., \& Palaniappan, B. (2011). An automated tsunami alert system, international journal of embedded system application (IJESA), Volume 1 no. 2.

Revell, A. (2013). GPU Implementation of Lattice Boltzmann Method with Immersed Boundary: observations and results. The Oxford e-Research Centre Many-Core Seminar Series.

Thurey, N. (2003). A single-phase freesurface Lattice-Boltzmann Method. M.Phil. thesis, FRIEDRICHALEXANDER-UNIVERSITAT ERLANGEN-NURNBERG.

Thurey, N., \& dkk. (2006). Animation of open water phenomena with couple shallow water and free surface simulations. Eurographics/ACM SIGGRAPH symposium on computer animation.

Ward, S. N. (2000). Landslide Tsunami. Journal of Geophysical Research, Volume 1 no 8.

Zakia, Z. (2004). Gempa dan Tsunami Getarkan Aceh. Retrieved Juli 19, 2013, from http://nationalgeographic.co.id/berita /2012/12/26-desember-2004-gempadan-tsunami-getarkan 
E. Moningkey ${ }^{1}$, R. Pardanus ${ }^{2}$, Jurnal Sains dan Teknologi, Universitas Negeri Manado www.unima.ac.id/lppm/efrontiers

\section{THIS PAGE IS INTENTIONALLY LEFT BLANK}

